\title{
The influence of application hyperaccumulator plant straw on photosynthetic pigment content and photosynthetic parameter of lettuce under cadmium stress
}

\author{
Le Liang ${ }^{1}$, Qiaoman $\mathrm{Ao}^{2}$, Ying Zhu², Yan Zhao ${ }^{2}$, Ran Zhang ${ }^{2}$ and Yi Tang ${ }^{\text {* }}$ \\ ${ }^{1}$ Institute of Pomology and Olericulture, Sichuan Agricultural University, Chengdu, Sichuan, 611130, China \\ ${ }^{2}$ College of Horticulture, Sichuan Agricultural University, Chengdu, Sichuan, 611130, China \\ *Corresponding author's e-mail: 95459425@qq.com
}

\begin{abstract}
Pot experiments were conducted to study the effects of straw application of three hyperaccumulator plants (Solanum nigrum, Bidens pilosa and Galinsoga parviflora) influence photosynthetic pigments content and photosynthetic parameters of lettuce (Lactuca sativa) under Cd stress. The results showed that: compared with no straw application, the photosynthetic pigment content of lettuce was increased by applying three kinds of hyperaccumulator plants straw (S. nigrum, B. pilosa and G. parviflora), but there was no significant difference among the three kinds of hyperaccumulator plant straws; also improved the net photosynthetic rate $(\mathrm{Pn})$, Stomatal conductance (Gs), transpiration rate $(\mathrm{Tr})$, intercellular $\mathrm{CO} 2$ concentration $(\mathrm{Ci})$ of lettuce, among them, the effect of G. parviflora straw was the most obvious. Application of three kinds of hyperaccumulator plant straw promoted the growth of lettuce by increasing the photosynthetic pigment content and photosynthetic parameter of lettuce under Cd stress.
\end{abstract}

\section{Introduction}

Straw returning is an agricultural measure being vigorously promoted, which can avoid air pollution caused by straw burning, it can also promote crop growth by improving soil fertility and soil properties, and reduce the bioavailability of heavy metals such as copper, cadmium $(\mathrm{Cd})$ and zinc [1]. One of many heavy metals, $\mathrm{Cd}$ pollution in soil mainly comes from transportation, agricultural inputs, sewage irrigation and sludge fertilization [2]. Cd can seriously harm plants and affect human health, there are many ways to alleviate $\mathrm{Cd}$ toxicity: intercropping [3], grafting [4], application of biomass charcoal [5] and so on. Applying straw of Tagetes erecta and Solanum photeinocarpum to Cd-contaminated soil at $10 \mathrm{mg} / \mathrm{kg}$ significantly increase tomato biomass and photosynthetic pigments content, and significantly decrease $\mathrm{Cd}$ content [6]. Hyperaccumulator plant can effectively repair heavy metal pollution. Soil application of hyperaccumulator plant straw has little research on $\mathrm{Cd}$ accumulation in leafy vegetables. Therefore, this experiment explored the effects of hyperaccumulator plant straw on photosynthetic pigments and photosynthetic parameters of lettuce under $\mathrm{Cd}$ pollution. It provides a new method for leafy vegetables to alleviate heavy metal pollution.

\section{Materials and Methods}

\subsection{Materials}

In June 2015, three kinds of Cd hyperaccumulator plants were collected from the surrounding farmland (not contaminated by heavy metals) in the Sichuan Agriculture University: Solanum nigrum, Bidens pilosa and Galinsoga parviflora, after removed the seeds, they were washed with distilled water. After 15 minutes of killing fresh at $105{ }^{\circ} \mathrm{C}$, they are dried to constant weight at $75{ }^{\circ} \mathrm{C}$. Cutting the dried straw into about $1 \mathrm{~cm}$ segments and set aside.

Lettuce is a common glass lettuce in Sichuan, it has high purity, good quality, good tolerance and resistance, and can be planted all year round and sustainable harvest for more than 50 days.

The tested soil was paddy soil, which was taken from farmland not polluted by heavy metals around Chengdu campus of Sichuan Agricultural University, its basic physical and chemical properties are as follows: $\mathrm{pH} 6.36$, organic matter $18.10 \mathrm{~g} / \mathrm{kg}$, total nitrogen $1.04 \mathrm{~g} / \mathrm{kg}$, total phosphorus $1.36 \mathrm{~g} / \mathrm{kg}$, total potassium $20.78 \mathrm{~g} / \mathrm{kg}$, hydrolyzable nitrogen $43.90 \mathrm{mg} / \mathrm{k}$, available phosphorus $92.71 \mathrm{mg} / \mathrm{kg}$, available potassium $134.25 \mathrm{mg} / \mathrm{kg}$, available $\mathrm{Cd}$ not detected. $\mathrm{CdCl}_{2} 2.5 \mathrm{H}_{2} \mathrm{O}$ analytical pure solution was added to the tested soil for heavy metal $\mathrm{Cd}$.

\subsection{Experimental design}

In June 2015, the air-dried and crushed soil was sifted through 300 meshes and loaded into barrels, each containing $20 \mathrm{~kg}$. The $\mathrm{Cd}$ concentration was $10 \mathrm{mg} / \mathrm{kg}$ by adding analytical pure $\mathrm{CdCl}_{2} 2.5 \mathrm{H}_{2} \mathrm{O}$ solution [7], after 
30 days of moist storage, all contaminated soils were fully blended and packed in a pot of $3 \mathrm{~kg}$ per pot.

Full lettuce seeds were select for disinfection, evenly spread them on wet gauze, put them into $20{ }^{\circ} \mathrm{C}$ light incubator for germination, and then sow them in a pot dish with nutritive soil to raise seedlings. After one week of lettuce seedling raising, three kinds of hyperaccumulator plant straw were applied to the prepared Cd contaminated soil, 6 g per pot, and mixed evenly, with no straw as the control. The experiment was divided into four treatments: no straw, $S$. nigrum straw, $B$. pilosa straw and $G$. parviflora straw. After a week of balancing and watering, selected healthy lettuce seedlings and transplant them into Cd-contaminated soil prepared with straw. Four plants were transplanted in each pot and nine pots were treated in each pot. After transplanting, the seedlings were placed in plastic greenhouse, and the soil moisture was maintained at about $80 \%$. After the lettuce grew 50d, chlorophyll content and photosynthetic parameters of lettuce were determined.

\subsection{Index determination}

Determination of chlorophyll content by acetone-ethanol mixture method [8]. Measurement of net photosynthetic rate $(\mathrm{Pn})$ by LI-6400 XT portable photosynthetic meter, stomatal conductance (Gs), transpiration rate (Tr), intercellular $\mathrm{CO} 2$ concentration $(\mathrm{Ci})$. The intrinsic light intensity was set at $1000 \mu \mathrm{mol} /(\mathrm{m} 2 \cdot \mathrm{s})$, the concentration of $\mathrm{CO}_{2}$ was $400 \mu \mathrm{l} / \mathrm{L}$, and the temperature was $25^{\circ} \mathrm{C}$ [9].

\subsection{Statistical analyses}

All data are collated with Excel 2010 software; SPSS 20.0 was used for variance analysis and Duncan's new complex range method was used for multiple comparisons.

\section{Results}

\subsection{Effects of soil application of hyperaccumulator plant straw on photosynthetic pigment content in lettuce leaves}

Application of hyperaccumulator plant straw increased the chlorophyll content of lettuce (Table 1). The application of $B$. pilosa straw and G. parviflora straw significantly increased chlorophyll a content in lettuce leaves. The content of chlorophyll a in lettuce leaves treated with $B$. pilosa straw was the highest, $25.27 \%$ higher than that of the control $(\mathrm{P}<0.05)$. When application B. pilosa straw, lettuce had the highest chlorophyll b content, but there was no significant difference among the treatments. The different trend of total chlorophyll content of lettuce was the same as that of chlorophyll a content. The order from high to low was B. pilosa straw $>G$. parviflora straw $>S$. nigrum straw $>$ no straw. The different trend of carotenoids in lettuce was the same as that of chlorophyll a and total chlorophyll. The carotenoid content of lettuce treated with $B$. pilosa straw was the highest, $42.86 \%$ higher than that of the control $(\mathrm{P}<0.05)$. The ratio of chlorophyll a to chlorophyll $\mathrm{b}$ in lettuce increased after the application of hyperaccumulator plant straw, and the treatment with G. parviflora straw was the highest.

Table 1. Effects of hyperaccumulate plant straw on the photosynthetic pigment of lettuce

\begin{tabular}{lccccc}
\hline \multicolumn{1}{c}{ Plant straw } & $\begin{array}{c}\text { Chlorophyll a } \\
(\mathrm{mg} / \mathrm{g})\end{array}$ & $\begin{array}{c}\text { Chlorophyll b } \\
(\mathrm{mg} / \mathrm{g})\end{array}$ & $\begin{array}{c}\text { Total chlorophyll } \\
(\mathrm{mg} / \mathrm{g})\end{array}$ & $\begin{array}{c}\text { Carotenoids } \\
(\mathrm{mg} / \mathrm{g})\end{array}$ & Chlorophylla/b \\
\hline No straw & $0.91 \pm 0.01 \mathrm{c}$ & $0.29 \pm 0.01 \mathrm{a}$ & $1.20 \pm 0.01 \mathrm{c}$ & $0.28 \pm 0.01 \mathrm{~b}$ & 3.14 \\
S. nigrum straw & $0.96 \pm 0.02 \mathrm{bc}$ & $0.29 \pm 0.01 \mathrm{a}$ & $1.25 \pm 0.03 \mathrm{c}$ & $0.35 \pm 0.01 \mathrm{ab}$ & 3.31 \\
B. pilosa straw & $1.14 \pm 0.01 \mathrm{a}$ & $0.33 \pm 0.01 \mathrm{a}$ & $1.47 \pm 0.01 \mathrm{a}$ & $0.40 \pm 0.01 \mathrm{a}$ & 3.45 \\
G. parviflora straw & $1.04 \pm 0.01 \mathrm{ab}$ & $0.30 \pm 0.01 \mathrm{ba}$ & $1.34 \pm 0.02 \mathrm{~b}$ & $0.37 \pm 0.01 \mathrm{ab}$ & 3.47 \\
\hline
\end{tabular}

Different lowercase letters in the same column indicate significant difference $(\mathrm{P}<0.05)$.

\subsection{Effects of soil application of hyperaccumulator plant straw on photosynthetic parameters of lettuce leaves}

All treatments increased $\mathrm{Pn}$ in lettuce leaves, there was no significant difference between $B$. pilosa straw and $G$. parviflora straw treatments, but they were significantly higher than no straw treatment, which increased by $14.06 \%(\mathrm{P}<0.05)$ and $14.06 \%(\mathrm{P}<0.05)$, respectively (Table 2). Leaf Gs of lettuce increased after the application of hyperaccumulator plant straw, and the order of its size was: $G$. parviflora straw $>S$. nigrum straw $>$ B. pilosa straw $>$ no straw, there was no difference among the treatments, but it was significantly higher than the control. For lettuce leaf $\mathrm{Ci}$, the application of $G$. parviflora straw increased by $6.13 \%$ compared with the control $(\mathrm{P}<0.05)$. Hyperaccumulator plant straw significantly increased leaf $\mathrm{Tr}$ of lettuce under Cd stress. The order of $\mathrm{Tr}$ in each treatment was as follows: $G$. parviflora straw $>B$. pilosa straw $>S$. nigrum straw $>$ no straw. The Tr of lettuce leaves was the highest after applying $G$. parviflora straw, 46.01\% significantly higher than that of the control $(\mathrm{P}<0.05)$. 
Table 2. Effects of hyperaccumulate plant straw on photosynthetic parameter of lettuce

\begin{tabular}{lcccc}
\hline Plant straw & $\begin{array}{c}\mathrm{Pn} \\
\left(\mathrm{mol} /\left(\mathrm{m}^{2} \mathrm{~s}\right)\right)\end{array}$ & $\begin{array}{c}\mathrm{Gs} \\
\left(\mathrm{mol} /\left(\mathrm{m}^{2} \mathrm{~s}\right)\right)\end{array}$ & $\begin{array}{c}\mathrm{Ci} \\
(\mathrm{mol} / \mathrm{mol})\end{array}$ & $\begin{array}{c}\mathrm{Tr} \\
\left(\mathrm{mmol} /\left(\mathrm{m}^{2} \mathrm{~s}\right)\right)\end{array}$ \\
\hline No straw & $13.58 \pm 1.06 \mathrm{c}$ & $0.26 \pm 0.02 \mathrm{~b}$ & $285.37 \pm 10.36 \mathrm{~d}$ & $3.26 \pm 0.18 \mathrm{~d}$ \\
S. nigrum straw & $15.76 \pm 1.29 \mathrm{a}$ & $0.39 \pm 0.02 \mathrm{a}$ & $290.72 \pm 13.13 \mathrm{c}$ & $4.54 \pm 0.11 \mathrm{~b}$ \\
B. pilosa straw & $15.49 \pm 0.60 \mathrm{~b}$ & $0.36 \pm 0.03 \mathrm{a}$ & $297.36 \pm 4.19 \mathrm{~b}$ & $4.28 \pm 0.23 \mathrm{c}$ \\
G. parviflora straw & $15.49 \pm 1.12 \mathrm{~b}$ & $0.40 \pm 0.02 \mathrm{a}$ & $302.87 \pm 3.57 \mathrm{a}$ & $4.76 \pm 0.13 \mathrm{a}$ \\
\hline
\end{tabular}

Different lowercase letters in the same column indicate significant difference $(\mathrm{P}<0.05)$.

\section{Conclusion}

Under Cd stress, the chlorophyll content of lettuce leaves was significantly increased by applying straw from hyperaccumulator plants ( $S$. nigrum straw, B. pilosa straw and G. parviflora straw) in soil, but there was no significant difference among treatments; the photosynthetic parameters of $G$. parviflora straw increased most obviously when applied. Therefore, under the condition of $\mathrm{Cd}$ pollution, the application of three hyperaccumulator plants straws $(S$. nigrum straw, $B$. pilosa straw and $G$. parviflora straw) were conducive to the normal growth of lettuce.

\section{References}

1. Cheng, G., Huan, Z., Zhang, H., Liu, Y. (2017) Research progress on the effect of straw returning on the environmental behavior of "paddy field mercury" in mercury polluted areas. SCIENCE CHINA PRESS, 62(24):2717-2723.

2. Pang, R., Wang, R., Xie, H., Guo, L., Li, J. (2016) Cadmium pollution in agricultural soil and analysis of pollution path. Tianjin Agricultural Sciences, 22(12):87-91.

3. Chen, H., Lin, L., Liao, M., Wang, J., Tang, Y., Sun. G., Liang, D., Xia, H., Deng, Q., Wang, X., Lv, X., Ren, W. (2019) Effects of intercropping with floricultural accumulator plants on cadmium accumulation in grapevine. Environmental Science and Pollution Research. https://doi.org/10.1007/s11356-019-05697-8.

4. Xia, H., Wang, Y., Liao, M., Lin, L., Zhang, F., Tang, Y., Zhang, H., Wang, J., Liang, D., Deng Q., Lv, X., Chen, C., Ren, Wei. (2019) Effects of different rootstocks on cadmium accumulation characteristics of the post-grafting generations of Galinsoga parviflora. International Journal of Phytoremediation. https://doi.org/10.1080/15226514.2019.1644287

5. Zhang, J., Zhou, S., Sun, H., Zhang, X. (2018) Research status and prospect of biomass charcoal application in vegetable fields in China. RESEARCH OF AGRICULTURAL MODERNIZATION, 39(4): 543-550.

6. Lin, L., Chen, F., Wang, J., Liao, M., Lv, X., Wang, Z., Lia, H., Deng, Q., Xia,H., Liang, D.,
Tang, Y., Wang, X., Lai, Y., Ren, W. (2018) Effects of living hyperaccumulator plants and their straws on the growth and cadmium accumulation of Cyphomandra betacea seedlings. Ecotoxicology and Environmental Safety, 155:109-116.

7. Lin, L., Liu, Q., Shi, J., Sun, J., Liao, M., Mei, L. (2014) Intercropping different varieties of radish can increase cadmium accumulation in radish. Environmental Toxicology and Chemistry, 33(9): 1950-1955.

8. Chang, M., Wei, X., Wang, Q., Hu, Y., Li, C., Tang, Y. (2016) Comparative study on different extraction methods of plant chlorophyll content. Chinese Agricultural Science Bulletin, 32(27): 177-180.

9. Xu, X., Sun, Y., Guo, X., Sun, B., Zhang, J. (2011) Effects of exogenous melatonin on photosynthesis and chlorophyll fluorescence of cucumber seedlings under temperature stress. Journal of Nuclear Agricultural Sciences, 25(1): 179-184. 